\title{
Comunicación política en Costa Rica: la experiencia de VotoCR
}

\section{Political communication in Costa Rica: the VotoCR experience}

\author{
Marlon Mora Jiménez \\ Centro de Estudios Generales \\ Universidad Nacional \\ Heredia, Costa Rica \\ marlonmoracr@gmail.com
}

\begin{abstract}
Resumen
Este trabajo sistematiza la experiencia del proceso electoral reciente y estudia la comunicación política en Costa Rica: estrategia e imágenes políticas hacia la Presidencia de la República 20142018. Apunta hacia los aportes en materia de comunicación política dentro de la campaña de la elección presidencial. Se basa en el proyecto de investigación "La comunicación política en Costa Rica: estrategia e imágenes políticas hacia la Presidencia de la República 2014-201”, del Centro de Estudios Generales de la Universidad Nacional de Costa Rica. Los medios sociales son una extensión natural del proyecto, así como la creación interactiva de un sitio web, que permite la comunicación, información y desarrollo de trabajos sistemáticos a la luz del ADN de la campaña electoral. La investigación se presenta en el marco del Congreso Centroamericano de Comunicación "La comunicación como herramienta para el desarrollo social".
\end{abstract}

Palabras claves: Comunicación política, elecciones, campaña electoral, medios sociales, votocr. 


\begin{abstract}
This work systematizes the Costa Rican experience of the recent election process and studies political communication in Costa Rica: political strategy and images towards the 2014-2018 Presidency of the Republic. It addresses the contributions in political communication inside the presidential elections campaign. It is based on the research project titled "Political communication in Costa Rica: political strategy and images towards the 2014-2018 Presidency of the Republic", of the General Studies Center of Universidad Nacional de Costa Rica. Social media are a natural extension of the project, as well as the interactive creation of a web site, which allows communication, information, and development of systematic works in the light of the DNA of the election campaign. The investigation is presented inside the frame of the Central American Congress on Communication, "Communication as a tool for social development".
\end{abstract}

Keywords: Political communication, elections, electoral campaign, social media and votocr.

\title{
Introducción
}

"Ya no basta con ganar unas elecciones, los ciudadanos comienzan a exigir transparencia en la acción de gobierno y posibilidades de participación”. Evoca Comunicación e Imagen

$\mathrm{E}$ ste artículo fue presentado como ponencia en el IV Encuentro de Humanidades "Participación ciudadana, humanismo y compromiso social: entre la teoría y la práctica", celebrado en junio del 2013 en Liberia, Guanacaste, Costa Rica. Ha sido enriquecido para esta publicación y próximamente será presentado en el Congreso de Centroamericano de Comunicación.

El propósito de esta producción es socializar conclusiones encontradas en el proceso electoral, que destilaron la comunicación política de los partidos, pero también la generación de opinión adquirida por parte de las audiencias: que desembocó en un cambio de gobierno y la llegada por primera vez a la silla presidencia del Partido Acción Ciudadana (PAC).

Se muestran antecedentes de la comunicación y la política, que constituyen posteriormente un marco teórico referencial para poder argumentar las posibles razones de la llegada a la presidencia de un partido diferente al tradicional. En el razonamiento de ese proceso, se mencionan aciertos y desaciertos de los candidatos. 


\section{El inicio: la comunicación y la política}

Los inicios de la comunicación política yacen en los orígenes de la civilización, cuando la vida social de las comunidades dependía de líderes y pensadores con grandes habilidades en el manejo de la retórica, la elocuencia y otras habilidades para comunicar sus ideas y sus propósitos.

La democracia, en su concepto más básico, desde las democracias representativas en los procesos electorales, reactiva estrategias y herramientas discursivas para hacer comunicación política ${ }^{1}$, en ocasiones cargada de información que busca convencer, disuadir o simplemente mercadear una idea. Para ello, el gobierno, los partidos políticos y la sociedad civil se presentan en un esquema de fuerzas centrífugas donde fluyen esas intenciones, que se verán reflejadas en la opinión pública.

La comunicación se convierte en un proceso fundamental para hacer política, entendida esta como la lucha por el poder y sus diversos escenarios para el establecimiento de prioridades y agendas de políticas públicas. Así lo explican Fernández et al. (2007) cuando se refieren al marketing político e imagen del gobierno, que serán fundamentales en el análisis y reflexiones finales, vistas como perspectivas a futuro en este trabajo.

\section{Congreso Centroamericano de Comunicación}

En el marco del Congreso Centroamericano de Comunicación "La comunicación como herramienta para el desarrollo social", este proyecto se ubica en el eje temático de comunicación y política, porque la investigación realizada permite la participación de diferentes audiencias (estudiantes de universitarios, académicos, investigadores, periodistas y usuarios de medios sociales en twitter o facebook, entre otros) con el compromiso de informar de las elecciones nacionales, lo cual lleva la teoría de la comunicación hacia la práctica.

Este tipo actividades académicas propician la interacción y promocionan la participación abierta, la discusión crítica y la reflexión en equipo. Además, el proyecto permite el intercambio entre usuarios: una experiencia valiosa al tener como referente la necesidad de los ciudadanos a estar informados de la campaña electoral. Al final, el balance y la cercanía de la información han logrado consolidar lo que en un inicio fue concebido desde la teoría: ahora una vivencia abierta de la realidad nacional.

${ }^{1}$ Un área del saber que estudia aquellas dinámicas de comunicación que se producen en períodos de gobierno y en período electoral. 
Para el Centro de Estudios Generales (CEG) de la Universidad Nacional (UNA), este es un importante proyecto que marca en el imaginario social la potencia de esa visión humanista de nuestra casa, porque en este mismo espacio académico se generaron debates de candidatos a la presidencia. Se contó, además, con la consulta pública sobre la visión de los derechos humanos, la educación para la paz, la administración pública, la ecología, la teoría de género, la gobernabilidad y el humanismo como punto central.

Otro aporte de esta investigación fue implementar la teoría de la comunicación política - poco trabajada en el país y sin publicaciones con ese enfoque- y también la participación ciudadana producto de la interacción en medios sociales.

Un proyecto como este se concentra en las estrategias discursivas, las capacidades de los actores políticos (imagen y retórica), el reconocimiento de las diferentes audiencias, las herramientas del mensaje (nuevas tecnologías y mercadeo), la perspectiva de los derechos humanos y los medios de comunicación como empresas en ese conclave de manifiestos, donde todo estará al servicio de la difusión de la Universidad Nacional como generadora de opinión y como gestora de planteamientos novedosos en una materia con poco estudio en el país.

\section{El proyecto}

Este proyecto de investigación pone de manifiesto un análisis denso y potente a la luz de la comunicación política realizada por los candidatos a la Presidencia de la República de Costa Rica en diferentes momentos de ese proceso: precampaña, campaña y primeros seis meses de gobierno, un trabajo que trasciende la experiencia digital, lo cual se explica más adelante.

Entendida esta serie de etapas, se presenta la experiencia vivida en la campaña de cierre electoral y se concentra en elementos para las conclusiones, con el fin de hacer énfasis en la comunicación política, aciertos y desaciertos.

Existe poca bibliografía sobre comunicación política en el país, así como trabajos escritos de análisis de campañas electorales en Costa Rica desde la visión de un comunicador. Por esto, se retoma de manera más sólida la fundamentación del intercambio político desde Javier del Rey Morato, reforzada por las estrategias e imágenes utilizadas por autores como Morris (1996), Sartori (1998), Magariños (2001) o Miravalles (2002), para la elaboración de esta ponencia en el Congreso Centroamericano de Comunicación. 
Se toman como referencia aspectos de la escuela española, donde se destaca la importancia de la "comunicación política de los candidatos para alcanzar sus propósitos" en un posible gobierno (Canel, 1999; Morato, 2007).

En ese sentido, hay que señalar la poca teorización versus práctica de la comunicación política, en ocasiones mal comprendida como la propaganda o la publicidad política. La comunicación política apenas emerge y son pocos los estudios que se hacen desde las ciencias de la comunicación. Por ello, este trabajo podría aportar ese esfuerzo por teorizar la comunicación política:

La comunicación política es un término amplio, apenas utilizado en el mundo profesional, que incluye una serie de fenómenos comunicativos como la propaganda, el marketing electoral, el marketing político, las relaciones públicas o la comunicación institucional política. (Canel, 1999, p. 15)

Para este artículo, la política adopta y aplica las decisiones para la comunidad. En este proceso su ligamen con la comunicación traspasa e incide en la esencia de la comunicación política (Canel, 1999; Miravalles, 2002; Morato, 2007), lo cual permite tomar las decisiones, al concatenar el intercambio de signos que al cierre detonarán en los aciertos y desaciertos de los candidatos a la presidencia.

La comunicación política trata de poner de manifiesto las ideas de los candidatos en las audiencias para que mediante la comunicación logren llegar al "poder para el bienestar de los gobernados" (Morato, 1997). Por eso, nuestro sitio web brinda al servicio de la audiencia una batería de componentes de la campaña electoral.

Estas son de las premisas de la investigación ${ }^{2}$ al contrastar que "en la teoría la comunicación política habla del bienestar de las personas" (Miravalles, 2002; Morato, 2007 y Canel, 1999) y en ese proceso muchas veces se vivencian otros escenarios propios de la vida política de los candidatos (donde una imagen o una mal manejo de comunicación en crisis puede "dar al traste" con todo).

El libro de Giovanni Sartori (1997) Homo videns (la sociedad teledirigida) es fundamental en su crítica a la actual sociedad multimedia, en la que el dominio de la imagen sobre la palabra escrita está transformando al ser humano, "un homo sapiens, en un homo videns": alguien en quien toda acogida de información está basada primordialmente en imágenes, lo cual conlleva una serie de peligros. A este asunto apuntan las campañas electorales que han sido estudiadas, revisadas y analizadas por el equipo director.

\footnotetext{
${ }^{2}$ La comunicación política de los candidatos y las manifestaciones de las audiencias.
} 
Finalmente, y no menos importante, como lo plantea Javier del Rey Morato (2007), sociólogo, profesor de Ciencias de la Información, en Los políticos siguen enredados en los viejos juegos de lenguaje. Y cuando plantea el lenguaje apunta a la Internet, que cambió los modos de la comunicación política, pero no todavía los contenidos y maneras de argumentar y vincular a los ciudadanos con la vida política:

\begin{abstract}
Así, las nuevas tecnologías de la comunicación y sus usos -páginas web, blogs y blogueros, foros y redes virtuales, correo electrónico, chat y chateos, Facebook y ahora Twitter- abren nuevos espacios y canales de participación, y también nuevos campos de expresión y de disputas. Vemos replicadas, en ese ciberespacio o "blogósfera" las cuestiones y debates clásicos de la democracia: nuevas formas de libertad, pretensiones de control y una interminable oferta de evasión y entretenimiento. (Morato, 2007)
\end{abstract}

Eso que el autor llama "la tríada de la posmodernidad internáutica" es parte del análisis a realizar desde un marco teórico que explique lo sucedido al cierre de la campaña electoral. Mientras las sociedades se deslizan de la teledemocracia a la ciberdemocr@, cia, tal parece que los políticos siguen jugando los viejos juegos de lenguaje.

Así se desea mostrar lo sucedido en materia de comunicación política electoral: las realidades presentadas por los diversos actores ante los posibles votantes, sean estos partidarios o no.

Los medios de comunicación colectiva han transformado la vida de las personas y su relación con el entorno, porque construyen un lenguaje social específico, que hace cambiar nuestras percepciones sobre la sociedad y nuestros vínculos con los demás.

En nuestro tiempo, tal parece que no podemos reducir la política a un término comunicativo, nada más; sin embargo, la política si necesita de la comunicación para lograr que su mensaje tenga el efecto requerido. Por eso, la comunicación política es más que un gabinete o una zona de prensa gubernamental y esa será nuestra tarea en esta ponencia con diferentes aportes en la democratización de medios de comunicación, la generación de opinión y, por ende, de la opinión pública, las apuestas por el marketing político y la necesidad de una ética de la comunicación en el momento de informar. 
El ejemplo más cercano que podemos tener en el imaginario costarricense es el ministerio de información, tomado en dos ocasiones por personas sin adiestramiento en comunicación que llevaron a la Presidencia 2010 - 2014, de Laura Chinchilla, a penurias y experiencias negativas. Primero, Roberto Gallardo y, luego, Francisco Chacón demostraron que no se necesita de un "político experto", sino de un vocero solvente que pueda informar bien: haciendo comunicación política institucional.

Este proyecto explica el ligamen entre la comunicación y la política en el proceso electoral hacia la presidencia 2014, desde un análisis de la campaña en imágenes, discursos y planes de gobierno. De este modo, se expone a continuación parte de la experiencia y el análisis realizado por VotoCR, como se le conoce a este proyecto universitario en redes.

\section{Experiencia de VotoCR}

El proyecto ha buscado desarrollar distintos espacios de difusión. Para iniciar, se creó una página o sitio web llamado votocr.com, donde las personas pueden conocer información valiosa de la campaña electoral, detalles de cómo acceder a la comunidad establecida para socializar de manera digital y toda la información generada por este estudio. (Ver figuras 1 y 2 )

Figura 1. Sitio web VotoCR

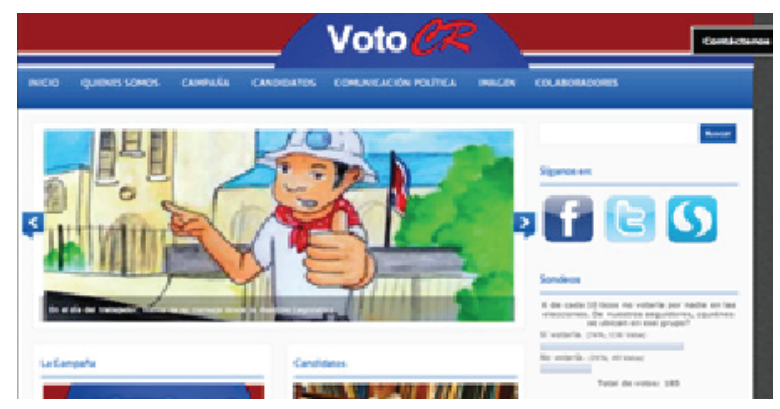

Fuente: Creación propia del proyecto.Recuperado de http://votocr.com 
Figura 2. Accesibilidad en medios sociales

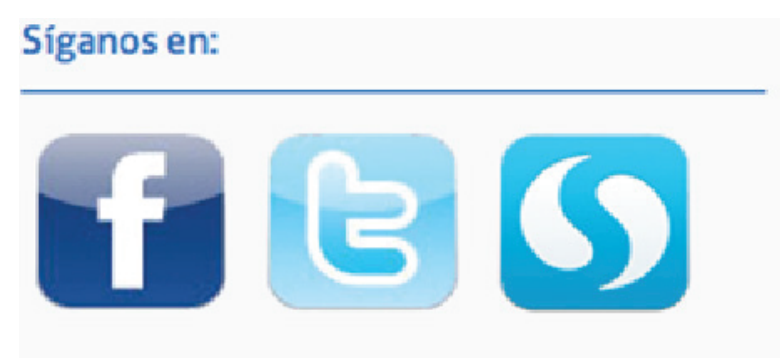

Fuente: Creación propia del proyecto.

De este modo, como se puede observar en la Figura 2, para potenciar espacios de socialización en redes sociales se crearon cuentas donde las personas pueden interactuar entre sí y con la dirección del proyecto, tal es el caso de Facebook, en la dirección https://www.facebook.com/Votocr; en Twitter, mediante el sitio https://twitter.com/votocr o en storify en la web http://storify.com/marlonmoracr.

Figura 3. Nuestra fanpage votoCR

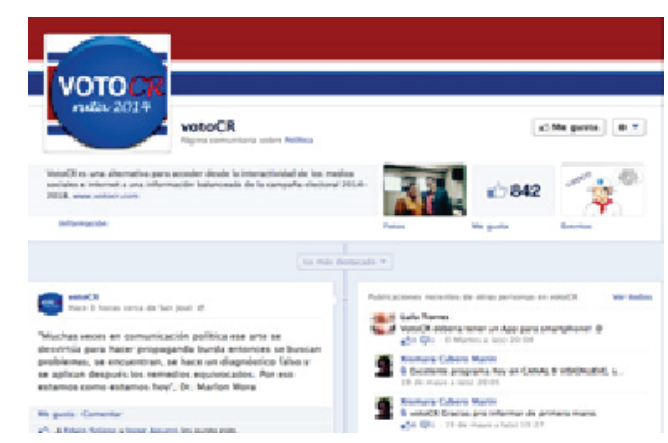

Fuente: Creación propia del proyecto. Recuperado de https://www.facebook. $\mathrm{com} /$ Votocr

En esta cuenta los usuarios pueden unirse a la página y con ello tener acceso a noticas, información, productos generados de la página principal, discutir y publicar puntos de vista de la campaña, entre otras acciones. 
Figura 4. Nuestro Twitter oficial @votoCR

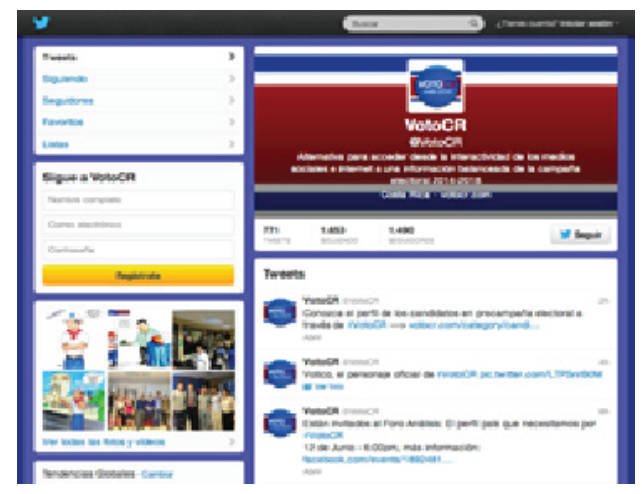

Fuente: Creación propia del proyecto. Recuperado de https://twitter.com/votocr

Gracias a Twitter, se puede generar opinión, compartir puntos de vista, expresar novedades o necesidades de la audiencia, entre muchas otras acciones. En la actualidad, nuestrotwitter@votoCR ha crecido de manera positiva con más de 4900 seguidores. Esto quiere decir que estamos interactuando diariamente con más de 7000 personas, si hablamos solo de contactos directos, a quienes hay que darles respuesta y atender a sus solicitudes. Si juntamos la plataforma de Facebook, logramos un alcance a más de 15 mil personas, según estadísticas publicadas.

Figura 5. Historial de noticias de precandidatos en Storify

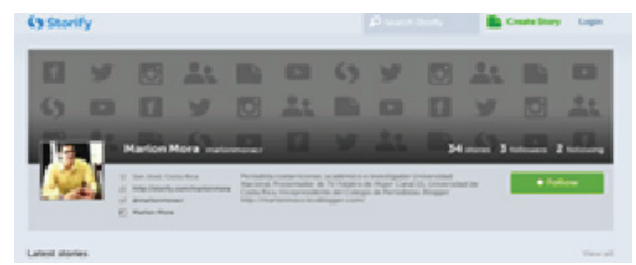

Fuente: Creación propia del proyecto. Recuperado de http://storify.com/ marlonmoracr

Finalmente, los medios sociales de Storify nos permiten realizar una recolección vertical - digitalizada de noticias sobre la campaña electoral por candidatos y también basados en temas de interés para el proyecto. Esto pone al alcance de la audiencia un valioso registro de noticias para entender la campaña electoral. 


\section{Sistematización y datos}

A través de estos espacios en medios sociales, se lograron recabar datos de las audiencias sobre los partidos políticos, también iniciar un proceso de razonamiento, referencia y crítica abierta, desde una triangulación de datos ofrecida por medios sociales, especialistas en foros, partidarios de candidatos y análisis de datos propios del proyecto.

En cuanto a la recolección, se basa en la búsqueda noticiosa de la comunicación política de los candidatos a la Presidencia de la República 2014-2018; tanto la prensa escrita, la televisión y los canales en la web prevén del insumo latente de la investigación. Mediante este análisis, se sintetizó el trabajo de los precandidatos para iniciar una serie de publicaciones en nuestros medios sociales.

A continuación, se explican brevemente las etapas del proyecto, con el fin de comprender el proceso metodológico realizado, de consulta, recolección de voces autorizadas y estudio de la administración del gobierno.

a. Acercamiento y recolección de principales ideas de precampaña con los equipos de trabajo de los participantes en este proceso electoral a lo interno de los partidos. Se construyeron los primeros análisis críticos del discurso y se explicitaron el pensamiento y las ideas de cada uno de los precandidatos. En esa etapa, se constataron principalmente las ideas y las imágenes más relevantes de la precampaña. Como producto, se creó una tabla de contenidos de los precandidatos, iniciada en el 2012, con las primeras manifestaciones de los participantes.

b. Como prueba material, se realizó una publicación con los perfiles de los precandidatos en un sitio web propio (votocr.com).

c. Luego de recolectadas y sistematizadas las precandidaturas, se inició otro proceso hacia la elección de la Presidencia de la República. Para ello el proyecto se enfocó en la construcción de los perfiles de los candidatos.

d. Este trabajo se realizó mediante entrevistas personales y recaudo de información a cada uno de los candidatos a la Presidencia. El ordenamiento fue un trabajo de la temporada (Recuadro 1). 


\section{Recuadro 1. Detalles de campaña}

Se efectuó una publicación de cada uno de los perfiles de los candidatos más importantes a la Presidencia de la República en el sitio oficial del proyecto con todos los datos de su comunicación política (logo, slogan, plan de gobierno, imágenes y principales ideas).

Además, se analizó cada uno de los planes de gobierno, imágenes, discursos, actos públicos, spots en redes sociales y medios de comunicación colectiva. En todo ese proceso se eligió la relevancia de la información y cómo se sistematizaba hacia el análisis de la comunicación política con los datos recolectados.

Fuente: Proyecto de investigación: "La comunicación política en Costa Rica: estrategia e imágenes políticas hacia la Presidencia de la República 2014-2018".

e. Para cerrar, luego de realizado este trabajo preelectoral, se inició un análisis de la comunicación política institucional, en este caso de Casa Presidencial, con el fin de recopilar los discursos y comunicación que incluía el plan de los primeros seis meses de gobierno.

Para el Congreso de Comunicación 2014, se consideró pertinente, además, presentar "datos duros" versus las vivencias del proceso en el cierre electoral. De este modo, la razón de ser de este proyecto -investigación dentro de una universidad estatal, la Universidad Nacional de Costa Rica- ha permitido desarrollar una plataforma de socialización de datos de la campaña electoral y la organización de debates con los candidatos a la Presidencia de la República de Costa Rica.

\section{Consideraciones finales}

VotoCR se perfiló como una posibilidad informativa, clasificadora de datos e investigaciones y plataforma electoral de gran credibilidad en el análisis e interpretación de los procesos electorales enrumbados hacia el 2014 con alianzas con medios de comunicación y resultados a la mano.

Foros con expertos, interacción en medios sociales, posiciones expresadas por ochenta estudiantes, aproximadamente, del CEG en dos semestres diferentes 
validan la visión de la juventud, así como los dos debates nacionales organizados con los candidatos a la presidencia que fueron transmitidos por dos canales de televisión estatales. Ante esto, se pone como antecedente la realidad de los principales candidatos a la presidencia con frases personales del autor para ubicar y señalar el estado de la situación. Inician en esta presentación: los partidos políticos, luego los candidatos presidenciales y, por último, las perspectivas a futuro en el marco de los aciertos y desaciertos.

\section{Partidos políticos}

- Existen pocos partidos consolidados, pero sí son muchas las agrupaciones políticas.

- La gente no quiere votar por el PLN, pero sí aparece en los primeros lugares de las casas encuestadoras. La gente sabe qué es el PLN.

- La gente pide una persona que responda rápidamente a los problemas del país.

- Mención desde los partidos pequeños merece José Miguel Corrales ${ }^{3}$, quien pudo ser presidente cuando estuvo en el PLN, pero no fue flexible con el proyecto país y eso la gente lo recuerda.

\section{Partido Acción Ciudadana}

Sobre Ottón Solís, fundador del PAC.

- "Si Dios le habla, Ottón Solís sería candidato por el PAC", como él mismo aseveró ${ }^{4}$. Una de la figura más fuerte de su partido, pero que gozaba del desgaste de campañas anteriores.

- Epsy Campbell no ganó ni en el propio PAC, es más fuerte fuera que dentro de su propio partido.

- Juan Carlos Mendoza es joven y no tuvo el temple para mover las masas, al final lo separaron en la precampaña solo 72 votos de quien hoy es presidente del país.

- Luis Guillermo Solís representa el perfil de lo que las audiencias piden, pero en precampaña le falta el performance suficiente y convincente para llegar al pueblo: asunto que lograría en enero del 2014.

\footnotetext{
${ }^{3}$ Candidato a la Presidencia de la República en el pasado por el Partido Liberación Nacional: ahora desde un partido pequeño no ha logrado la potencia de antaño

${ }^{4}$ Basado en declaraciones realizadas por el mismo Ottón.
} 


\section{Frente Amplio (FA)}

- José María Villalta atrae a los estudiantes universitarios: su discurso y su capacidad consecuente han logrado constatar en las redes esa afinidad con la juventud.

- Sin embargo, hay que decirlo, Costa Rica no está preparada para votar por un presidente de izquierda. La polarización en campaña fue un agente importante que jugó en contra de una encuesta que en algún momento pareció liderar.

\section{Partido Unidad Social Cristiana (PUSC)}

- Rodolfo Hernández, un médico que revivía la potencia de las garantías sociales, fue catapultado como un candidato viable. Sus incapacidades para conocer la política lo dejaron en el camino, para abrirle el camino a un nuevo personaje: Rodolfo Piza, un abogado constitucionalista, quien alcanzó revivir su partido con varias diputaciones alcanzadas.

\section{Partido Liberación Nacional (PLN)}

- La situación de ingobernabilidad -país- le afectó Johnny Araya, no cabe duda.

- Johnny apareció contundente en las encuestas, pero en una segunda ronda le fue imposible alcanzar la presidencia.

\section{Movimiento Libertario (ML)}

- Otto Guevara, un candidato de mil batallas, agotó su discurso y sus capacidades para negociar y acercarse a los grupos conservadores, en tiempos de diversidad, le "cobraron" un alto costo.

\section{Comunicación política: perspectivas del proceso}

La campaña electoral en Costa Rica empezó muy temprano, recién finalizaban los primeros 100 días de gobierno de la anterior presidente, Laura Chinchilla. Ya en su propio partido aparecía un candidato presidencial, Rodrigo Arias, hermano del expresidente Óscar Arias, reconocido internacionalmente por su papel en el proceso de paz de Centroamérica.

Ese recorrido propició un desgaste en PLN, donde varios candidatos arrancaron campaña antes de tiempo y la carrera de esta campaña electoral era para "fondista de maratón", no para "atletas de 100 metros cortos". 
Johnny Araya, candidato oficialista del PLN, se mantuvo vigente en las encuestas gracias a sus capacidades de ser conocido por un largo mandato en la Alcaldía de San José, capital de nuestro país. De este modo, sin precampaña, el oficialismo escogió a su candidato sin discusiones y con el respaldo de varios exprecandidatos.

Ya en el proceso de campaña electoral, 13 candidatos aspirarían a la presidencia, donde básicamente solo cinco aparecían en encuestas: Johhny Araya del PLN, Otto Guevera del ML, José María Villalta de FA, Rodolfo Piza del PUSC y Luis Guillermo Solís del PAC.

De este modo, en los últimos tres meses de la campaña, ante el liderazgo en redes sociales y potencia del discurso de un joven de izquierda, José María Villalta del FA también inició un proceso de choque por todos los medios de comunicación tradicionales y no alternativos (redes, blogs y actividades de grupos específicos).

Ese proceso de choque permitió visualizar un mapeo de candidaturas llamadas de izquierda y derecha: todo esto planteado más en los discursos que en sus mismos programas de gobierno.

Así, se ponía en el imaginario social un candidato de choque frente al joven de izquierda de Frente Amplio con uno de derecha y experimentado, Otto Guevara, político con 16 años en proceso electorales y diputado ya en la Asamblea Legislativa en el pasado. De este modo, todos parecían señalar la inexperiencia de José María Villalta del FA y los anuncios en televisión machacaban la misma idea. Anuncios de PLN, ML y PAC eran sistemáticos en maximizar baterías su contra.

Una polarización en una campaña a un mes de las elecciones con un partido que acostumbra a crecer en enero, como el Partido Acción Ciudadana puso de manifiesto una atípica campaña electoral.

Luis Guillermo Solís (PAC), profesor universitario, hombre de la política y con el carisma suficiente, creció aceleradamente al cierre de la campaña: luego de no aparecer en encuestas, se catapultó como ganador en solitario en primera ronda, aunque la diferencia porcentual con Johnny Araya lo obligaría a segunda ronda. 


\section{Aciertos y desaciertos: perspectivas de la realidad}

La comunicación política, la maximización de una nueva herramienta en el proceso electoral -redes sociales-, el gobierno de Laura Chinchilla, la realidad del país en términos de desigualdades y los debates de los medios más grandes marcaron un norte para decidir el voto.

Los nuevos votantes no eran los tradicionales de partidos políticos, sino una juventud crítica e interesada en cambios significativos. La potencia de Luis Guillermo Solís del PAC radicaba en ser un hombre "como usted y como yo". Por lo menos ese fue el discurso que se mostró en los más de 20 debates organizados, el cual contó y marcó diferencia.

Claro está que en toda la campaña electoral hubo diferentes matices para potenciar a quienes querían acceder al poder y pocas veces se conjugaban atribuciones e historias para hilvanar lo que fue el gane histórico del candidato del PAC. Uno de los elementos para catapultar esa votación fue la renuncia a la segunda ronda del candidato oficialista, Johnny Araya, luego de la publicación de una encuesta que aseguraba una pérdida estrepitosa.

La realidad, todos la sabemos ya, es que Luis Guillermo Solís se convirtió en un candidato apreciado hasta por la prensa. Ahora el estudio sigue recabando datos, pero de la administración del gobierno: esa será otra historia.

\section{Referencias}

Canel, M. (1999). Comunicación política, técnicas y estrategias para la sociedad de la información. Madrid, España: Tecnos S.A.

Fernández, C.; Hernández, R.; Ocampo, E. (2007). Marketing político e imagen de gobierno en funciones. Mexico: McGraw Hill.

Sartori, G. (2001). La sociedad multiétnica. Pluralismo, multiculturalismo y extranjeros. España: Taurus. 
Magariños, J. (2001). La semiótica de la imagen visual. Cuadernos de la Facultad de Humanidades y Ciencias Sociales. San Salvador: Universidad Nacional de Jujuy.

Miravalles, A. (2002). Periodismo, opinión pública y agenda ciudadana. Enciclopedia Latinoamericana de Sociocultura y Comunicación. Bogotá, Colombia: Grupo Editorial Norma.

Morato, J. (1997). Los juegos de los políticos. Teoría general de la información y comunicación política. Madrid, España: TECNOS.

Morato, J. (2007). Comunicación política, internet y campañas electorales. De la teledemocracia a la ciberdemocr@cia. Madrid, España: TECNOS. 